\title{
Increasing Organ Donation: We Can Do Better!
}

\section{Keith K. Lau ${ }^{1}$ and Lavjay Butani ${ }^{2 *}$}

${ }^{1}$ Department of Pediatric Nephrology, McMaster University, Hamilton, Ontario, Canada ${ }^{2}$ Department of Pediatric Nephrology, University of California Davis, Sacramento, CA, USA

One of the major tasks of the renal transplant community in the contemporary era is to combat the ever growing disparity between available organ donors and the number of patients on the renal transplant wait list. Although living donor transplantation is unquestionably superior to deceased organ transplantation $[1,2]$, the limited number of suitable living donors precludes the use of this option for most patients. As of December 2012 over a hundred thousand Americans were on the wait list to receive a renal transplant; equally distressing was the fact that just over 4000 patients died while on the wait list in 2012 before an allograft could be made available to them $[3,4]$. These distressing observations should be a call to arms for us to investigate other strategies to increase the availability of deceased donors, while at the same time aggressively promoting living donor transplantation within our community.

\section{Legislative Change to Increase Organ Donor Pool}

One such attempt is by enacting legislation which presumes that everyone has consented to be an organ donor unless specified otherwise by the individual (the 'presumed consent' or 'opt-out' policy) [5]. Studies from several different countries, especially European countries such as Spain, suggest that the adoption of opt-out policies are associated with higher deceased organ donation rates [5-8]. In January 2011 a presumed consent bill proposed in New York was withdrawn by its sponsor because of strong opposition [9]. Another similar bill proposed in Colorado was also dropped after facing substantial resistance [10]. Proposals akin to this have also been blocked in Canada and the United Kingdom $[11,12]$. There is ongoing debate regarding the appropriateness of the presumed consent policy, especially its ethical implications related to human rights and individual autonomy $[13,14]$. Another potential concern is the public mistrust that such legislation might generate, arising from fear that once people have consented to be organ donors, they might receive less aggressive medical care [15]. Ignoring these sentiments may promote adverse public perceptions of the medical profession and an increase in organ donor availability may not be realised, even if the law does get passed. Therefore, although the opt-out scheme is being seriously considered as an effective way to increase organ donation by the British Medical Association, the feasibility of implementing this policy remains contentious in many other countries including the United States [16-19]. The consistently unsuccessful legislative efforts thus far in passing the presumed consent law in the United States indicates that this approach needs more public support before further progress can be made [20].

\section{Maximizing Organ Procurement from Potential Donors}

One of the other major efforts is the U.S. Organ Donation Breakthrough Collaborative (ODBC), a nationwide collaborative sponsored by the Health Resources and Services Administration (HRSA) to maximize the procurement of potential donor organs, with a target donation rate of $75 \%$ or more from eligible donors [21,22]. Organ procurement organizations have partnered with hospitals to implement high leverage changes to advocate for organ donation [23]. These initiatives aim to minimize the failure to identify potential donors and to maximize the consent rate from families since data show that as many as 16 to $27 \%$ of potential donor grafts are not procured for a variety of easily addressable reasons such as lack of identification of potential donors by the health care team, or failure to educate and get informed consent from families of possible organ donors [24,25]. The presence of an experienced transplant coordinating team greatly aids in mitigating these logistic obstacles; other strategies include revising and publicizing organ donation criteria and optimizing the critical care management of potential donors to maintain viability of organs without compromising patient care [25-27]. Studies have shown that in-house coordinator programs have improved conversion rates for organ donation [28]. Obtaining consent from families for organ donation is another major obstacle. A study that involved 36 organ procurement organizations showed that only $54 \%$ of families gave consent for deceased organ donation [25]. There were also marked variations in consent rates by ethnicity, with minorities having much lower consent rates [29]. The use of culturally sensitive and competent transplant coordinators can address some of these discrepancies [28,30-33].

Although there was an improvement in the organ disparity numbers during the first few years after the inception of the ODBC, the wait list began to surge over the subsequent years such that the wait list numbers in the US have now increased to $101,160[4,34]$. Obviously, these and other initiatives alluded to above, have not been able to meet the growth in organ demand and as such other interventions are being considered. Some gains have been made, such as by utilizing organs previously thought of as being 'sub-optimal' (extended criteria and non- heart beating donors and the use of pediatric en-bloc kidneys) [35-39] but much work still remains to be done.

\section{Public Education Programs}

Efforts have been directed via online registries and licensing bureaus such as the Department of Motor Vehicles in order to bolster enrolment of members of the community as potential organ donors. Providing educational programs to primary care physicians about organ donation and transplantation can also enhance their ability to influence the attitudes of potential donors and increase their commitment to register as donors [40]. Although minority groups have been identified as being less willing to register as donors, recent studies have shown that a multifaceted approach that includes mass media campaigns, point-of-decision interventions and interpersonal interventions may improve registration rates [41-44].

\section{Financial Incentives}

Another potential obstacle to organ donation is the cost incurred by the family of the deceased donor. Experiences from other countries, such as Kuwait, support provision of some financial incentives such as reimbursement for travel and burial expenses, to increase the deceased

*Corresponding author: Lavjay Butani, Department of Pediatric Nephrology, University of California Davis, 2516 Stockton Blvd, Sacramento, CA 95817, USA Tel: 916-734-8118; Fax: 916-734-0629; E-mail: Lavjay.butani@ucdmc.ucdavis.edu

Received December 04, 2012; Accepted December 24, 2012; Published December 27, 2012

Citation: Lau KK, Butani L (2013) Increasing Organ Donation: We Can Do Better J Transplant Technol Res S2: e001. doi:10.4172/2161-0991.S2-e001

Copyright: ( 2013 Lau KK, et al. This is an open-access article distributed under the terms of the Creative Commons Attribution License, which permits unrestricted use, distribution, and reproduction in any medium, provided the original author and source are credited. 
donor rate. The National Kidney Foundation has also issued a position statement on increasing organ donation and transplantation in the United States in January 2009, hoping to 'end the wait' by eliminating barriers to organ donation, such as reimbursing any additional cost to donor families [45]. Although under the Organ Donation and Recovery Improvement Act (PL 108-216) the federal government has authorized $\$ 25$ million in program development, including a grant to overcome the financial burden for living donors, similar federal initiatives for deceased donation programs are lacking [46].

In summary, although the aforementioned strategies have resulted in some improvement in deceased donor registration rates in the United States, the wait list continues to get larger as demand exceeds supply. In response to this, the HRSA announced a 'Social and Behavioural Interventions to Increase Solid Organ Donation' grant to fund studies to evaluate 'highly promising strategies and approaches that can serve as model interventions for increasing solid organ donation' [47].

The time has come for the medical profession to take up this call to arms and promote the well being of those we have committed to care for.

\section{References}

1. Hariharan S, Johnson CP, Bresnahan BA, Taranto SE, McIntosh MJ, et al. (2000) Improved graft survival after renal transplantation in the United States, 1988 to 1996. N Engl J Med 342: 605-612.

2. Lamb KE, Lodhi S, Meier-Kriesche HU (2011) Long-term renal allograft survival in the United States: a critical reappraisal. Am J Transplant 11: 450-462.

3. OPTN. Death Removals by Region by Year. 2012 [updated November 23, 2012; cited 2012 December 1]; Available from: http://optn.transplant.hrsa.gov/ latestData/rptData.asp.

4. OPTN. Overall by Organ. 2012 [updated November 23, 2012; cited 2012 December 1]; Available from: http://optn.transplant.hrsa.gov/latestData/ rptData.asp.

5. Horvat LD, Cuerden MS, Kim SJ, Koval JJ, Young A, et al. (2010) Informing the debate: rates of kidney transplantation in nations with presumed consent. Ann Intern Med 153: 641-649.

6. Abadie A, Gay S (2006) The impact of presumed consent legislation on cadaveric organ donation: a cross-country study. J Health Econ 25: 599-620.

7. Mossialos E, Costa-Font J, Rudisill C (2008) Does organ donation legislation affect individuals' willingness to donate their own or their relative's organs? Evidence from European Union survey data. BMC Health Serv Res 8: 48.

8. Rithalia A, McDaid C, Suekarran S, Myers L, Sowden A (2009) Impact of presumed consent for organ donation on donation rates: a systematic review. BMJ 338:a3162.

9. Albany, NY - Proposed Presumed Consent Bill Dropped (2010).

10. Colorado Organ Donor Legislation Pulled (2011).

11. Verheijde JL, Rady MY, McGregor JL, Friederich-Murray C (2009) Enforcement of presumed-consent policy and willingness to donate organs as identified in the European Union Survey: the role of legislation in reinforcing ideology in pluralistic societies. Health policy $90: 26-31$.

12. Verheijde JL, Rady MY, McGregor JL, Murray CF (2008) Legislation of presumed consent for end-of-life organ donation in the United Kingdom (UK) undermining values in a multicultural society. Clinics 63: 297-300.

13. Pope TM (2010) Legal briefing: organ donation and allocation. J Clin Ethics 21: $243-263$

14. Saunders B (2010) Normative consent and opt-out organ donation. J Med Ethics 36: 84-87.

15. Bard JS (2012) Lack of political will and public trust dooms presumed consent. Am J Bioeth 12: 44-46.

16. Mayor S (2012) Opt-out scheme is still best way to increase organ donation, says BMA. BMJ 344:e1098

17. English $V(2007)$ Is presumed consent the answer to organ shortages? Yes. BMJ 334: 1088.
18. Zink S, Zeehandelaar R, Wertlieb S (2005) Presumed versus Expressed Consent in the US and Internationally. Vitual Mento 7.

19. Hamm D, Tizzard J (2008) Presumed consent for organ donation. BMJ 336 230.

20. Verheijde JL, Rady MY, McGregor J (2009) Presumed consent for organ preservation in uncontrolled donation after cardiac death in the United States: a public policy with serious consequences. Philos Ethics Humanit Med 4: 15.

21. Leichtman AB, Cohen D, Keith D, O'Connor K, Goldstein M, et al. (2008) Kidney and pancreas transplantation in the United States, 1997-2006: the HRSA Breakthrough Collaboratives and the 58 DSA Challenge. Am J Transplant 8 : 946-957.

22. Shafer TJ, Wagner D, Chessare J, Schall MW, McBride V, et al. (2008) US organ donation breakthrough collaborative increases organ donation. Crit Care Nurs Q 31: 190-210.

23. Marks WH, Wagner D, Pearson TC, Orlowski JP, Nelson PW, et al. (2006) Organ donation and utilization, 1995-2004: entering the collaborative era. Am J Transplant 6: 1101-1110.

24. Gortmaker SL, Beasley CL, Brigham LE, Franz HG, Garrison RN, et al. (1996) Organ donor potential and performance: size and nature of the organ donor shortfall. Crit Care Med 24: 432-439.

25. Sheehy E, Conrad SL, Brigham LE, Luskin R, Weber P, et al. (2003) Estimating the number of potential organ donors in the United States. N Engl J Med 349: 667-674.

26. Snell GI, Griffiths A, Macfarlane L, Gabbay E, Shiraishi T, et al. (2000) Maximizing thoracic organ transplant opportunities: the importance of efficient coordination. J Heart Lung Transplant 19: 401-407.

27. Rosendale JD, Chabalewski FL, McBride MA, Garrity ER, Rosengard BR, et al. (2002) Increased transplanted organs from the use of a standardized donor management protocol. Am J Transplant 2: 761-768.

28. Salim A, Berry C, Ley EJ, Schulman D, Desai C, et al. (2011) In-house coordinator programs improve conversion rates for organ donation. J Trauma 71: 733-736.

29. Siminoff LA, Lawrence RH, Arnold RM (2003) Comparison of black and white families' experiences and perceptions regarding organ donation requests. Crit Care Med 31: 146-151.

30. Siminoff LA, Gordon N, Hewlett J, Arnold RM (2001) Factors influencing families' consent for donation of solid organs for transplantation. JAMA 286 71-77

31. Eschenmoser G, Gachet C, Bettschart V (2002) Local coordination increases the number of organs available for transplantation. Transplant Proc 34: 841842

32. Shafer TJ, Ehrle RN, Davis KD, Durand RE, Holtzman SM, et al. (2004) Increasing organ recovery from level I trauma centers: the in-house coordinato intervention. Prog Transplant 14: 250-263.

33. Shafer TJ, Davis KD, Holtzman SM, Van Buren CT, Crafts NJ, et al. (2003) Location of in-house organ procurement organization staff in leve I trauma centers increases conversion of potential donors to actual donors. Transplantation 75: 1330-1335.

34. Punch JD, Hayes DH, LaPorte FB, McBride V, Seely MS (2007) Organ donation and utilization in the United States, 1996-2005. Am J Transplant 7: 1327-1338.

35. Hanf W, Codas R, Meas-Yedid V, Berthiller J, Buron F, et al. (2012) Kidney graft outcome and quality (after transplantation) from uncontrolled deceased donors after cardiac arrest. Am J Transplant 12: 1541-1550.

36. Glyda M, Wlodarczyk Z, Czapiewski W (2012) Results of renal transplantation from expanded criteria deceased donors - a single-center experience. Ann Transplant 17: 35-42

37. Hernadez-Alejandro R, Wall W, Jevnikar A, Luke P, Sharpe M, et al. (2011) Organ donation after cardiac death: donor and recipient outcomes after the first three years of the Ontario experience. Can J Anaesth 58: 599-605.

38. Young A, Kim SJ, Speechley MR, Huang A, Knoll GA, et al. (2011) Accepting kidneys from older living donors: impact on transplant recipient outcomes. Am J Transplant 11: 743-750.

39. Tittelbach-Helmrich D, Drognitz O, Pisarski P, Seifert G, Thomusch O (2010) Single kidney transplantation from young pediatric donors in the United States. Am J Transplant 10: 2179 
Citation: Lau KK, Butani L (2013) Increasing Organ Donation: We Can Do Better! J Transplant Technol Res S2: e001. doi:10.4172/2161-0991.S2e001

40. Bidigare SA, Ellis AR (2000) Family physicians' role in recruitment of organ donors. Arch Fam Med 9: 601-604.

41. Harrison TR, Morgan SE, King AJ, Williams EA (2011) Saving lives branch by branch: the effectiveness of driver licensing bureau campaigns to promote organ donor registry sign-ups to African Americans in Michigan. J Health Commun 16: 805-819.

42. Morgan SE, Harrison TR (2010) The impact of health communication research on organ donation outcomes in the United States. Health communication 25: 589-592.

43. Morgan SE, Stephenson MT, Afifi W, Harrison TR, Long SD, et al. (2011) The University Worksite Organ Donation Project: a comparison of two types of worksite campaigns on the willingness to donate. Clin Transplant 25: 600-605.
44. Thornton JD, Wong KA, Cardenas V, Curtis JR, Spigner C, et al. (2006) Ethnic and gender differences in willingness among high school students to donate organs. J Adolesc Health 39: 266-274.

45. NKF. End The Wait! 2009

46. GPO. Organ Donation and Recovery Improvement Act: Public Law 108-216. In: Information UG, editor.2004.

47. Maldonado R. Funding Opportunity Annoucement: Social and Behavioral Interventions to Increase Solid Organ Donation. U.S. Department of Health and Human Services; 2012

This article was originally published in a special issue, Endothelial Keratoplasty handled by Editor(s). Dr. Jodhbir S Mehta, Singapore Eye Research Institute, (SERI), Singapore; Dr. Saijad Ahmad, Newcastle University, United Kingdom 